\title{
Transcriptional analysis of cell growth and morphogenesis in the unicellular green alga Micrasterias (Streptophyta), with emphasis on the role of expansin
}

Katrijn Vannerum ${ }^{1,2,3}$, Marie JJ Huysman 1,2,3, Riet De Ryckee ${ }^{2,3}$, Marnik Vuylsteke ${ }^{2,3}$, Frederik Leliaert ${ }^{4}$, Jacob Pollier ${ }^{2,3}$, Ursula Lütz-Meindl ${ }^{5}$, Jeroen Gillard ${ }^{1,2,3}$, Lieven De Veylder ${ }^{2,3}$, Alain Goossens ${ }^{2,3}$, Dirk Inzée, ${ }^{2,3}$ and Wim Vyverman ${ }^{1 *}$

\begin{abstract}
Background: Streptophyte green algae share several characteristics of cell growth and cell wall formation with their relatives, the embryophytic land plants. The multilobed cell wall of Micrasterias denticulata that rebuilds symmetrically after cell division and consists of pectin and cellulose, makes this unicellular streptophyte alga an interesting model system to study the molecular controls on cell shape and cell wall formation in green plants.

Results: Genome-wide transcript expression profiling of synchronously growing cells identified 107 genes of which the expression correlated with the growth phase. Four transcripts showed high similarity to expansins that had not been examined previously in green algae. Phylogenetic analysis suggests that these genes are most closely related to the plant EXPANSIN A family, although their domain organization is very divergent. A GFP-tagged version of the expansin-resembling protein MdEXP2 localized to the cell wall and in Golgi-derived vesicles. Overexpression phenotypes ranged from lobe elongation to loss of growth polarity and planarity. These results indicate that MdEXP2 can alter the cell wall structure and, thus, might have a function related to that of land plant expansins during cell morphogenesis.

Conclusions: Our study demonstrates the potential of $M$. denticulata as a unicellular model system, in which cell growth mechanisms have been discovered similar to those in land plants. Additionally, evidence is provided that the evolutionary origins of many cell wall components and regulatory genes in embryophytes precede the colonization of land.
\end{abstract}

\section{Background}

Although the form and function of plant cells are strongly correlated, the processes that determine the cell shape remain largely unknown. Plant cell morphogenesis is regulated in a non-cell-autonomous fashion by the surrounding tissues [1], hormone interference during ontogenesis, and sometimes by polyploidy as a consequence of endoreduplication $[2,3]$. In contrast, in unicellular relatives of land plants, it is possible to study the endogenous controls of cell morphogenesis without the interference by interacting cells and to better

\footnotetext{
* Correspondence: Wim.Vyverman@UGent.be

'Laboratory of Protistology and Aquatic Ecology, Department of Biology, Ghent University, 9000 Gent, Belgium

Full list of author information is available at the end of the article
}

understand how these mechanisms have evolved in the green lineage.

The desmid Micrasterias denticulata is a member of the conjugating green algae (Zygnematophyceae) that comprise the closest extant unicellular relatives of land plants [4-8]. M. denticulata cells consist of two bilaterally symmetrical flat semicells, notched deeply around their perimeter into one polar lobe and four main lateral lobes. Following cell division, each semicell builds a new one through a process of septum bulging and symmetrical local growth cessations to form the successive lobes (Figure 1A). After completion of the primary wall (during the doublet stage), a rigid cellulosic secondary cell wall pierced by pores is deposited, followed by shedding of it. This peculiar growth mechanism makes

\section{C) Biomed Central}



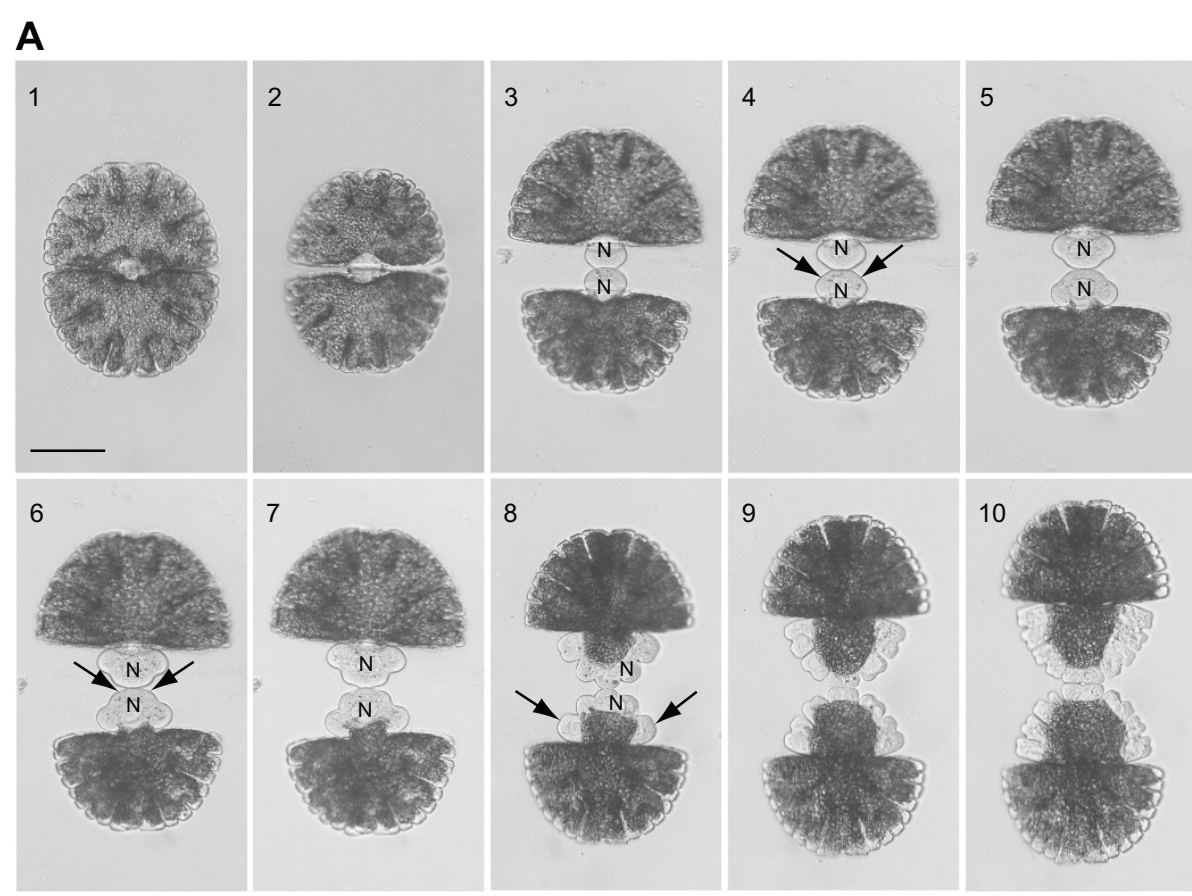

B
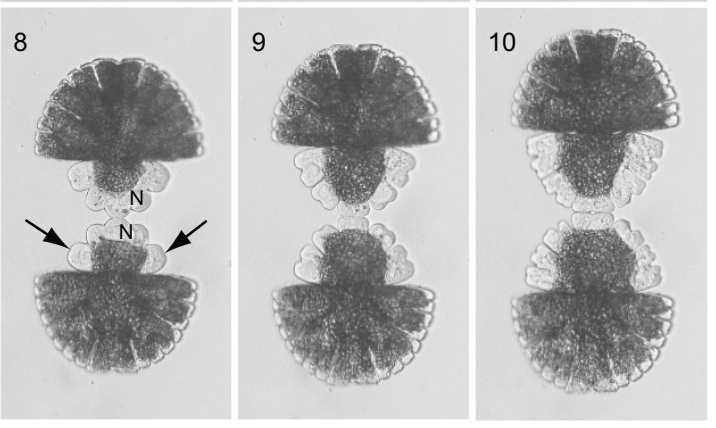

C

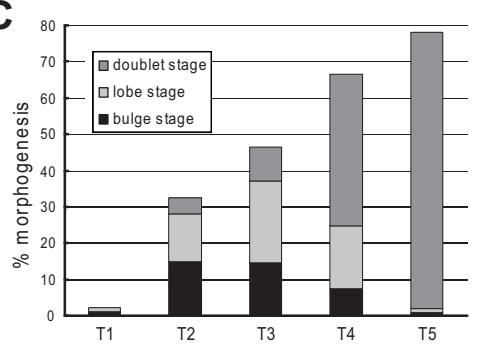

。

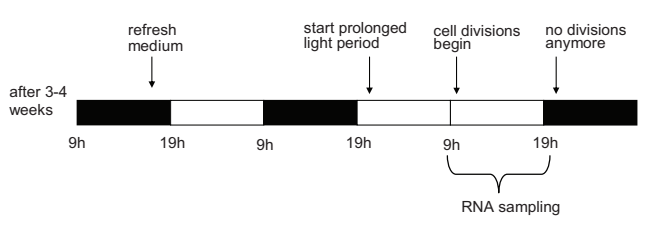

\begin{tabular}{|c|c|c|c|c|l|}
\hline T1 & T2 & T3 & T4 & T5 & sample \\
\hline 0 & 2,5 & 5 & 7,5 & 9 & relative time (hour) \\
\hline $1-2$ & $2-3$ & $2-9$ & $9-10$ & 10 & dominating morphogenetic stages (cf fig. A) \\
\hline $1-5$ & $10-15$ & $10-15$ & $5-10$ & 0 & $\%$ bulge stage \\
\hline $1-5$ & $1-10$ & $15-30$ & $15-25$ & 0 & $\%$ lobe stage \\
\hline 0 & $1-10$ & $5-15$ & $25-65$ & $50-85$ & $\%$ doublet stage \\
\hline
\end{tabular}

Figure 1 Morphogenesis of Micrasterias denticulata and distribution of morphogenetic stages in the synchronized sample series. (A) Morphogenesis of $M$. denticulata. (1) Vegetative cell. (2) During mitosis, a septum originating from the cell wall girdle grows inward centripetally, taking 15-20 min. (3) Bulge stage; the septum bulges uniformly. (4) Development of the first pair of indentations (arrows), 75 min after septum completion. (5) Three-lobed stage. (6) Development of the second pair of indentations (arrows). (7) Five-lobed stage. (8) Doubling of the lateral lobes (arrows). (9) Formation of further indentations and lobe tips, followed by the doublet stage. N, Nucleus. Note the migration of the nucleus during cell growth. Scale bar $=100 \mu \mathrm{m}$. (B) Scheme of the synchronization protocol. After 3-4 weeks, a stationary culture is obtained and the growth medium is refreshed, concomitantly with the reduction in cell density, shortly before the beginning of the light period of that day. The majority of the cells divide in the second dark period afterward. This dark period is replaced by a light period and sampled. Black, dark period; white, light period. (C), Distribution of morphogenetic stages in the RNA samples for CDNA-AFLP, replication 1. (D) Table representing the characteristics of the samples used for cDNA-AFLP (replications 1 and 2) and real-time qPCR.

Micrasterias an ideal model to study the spatial and temporal patterning of cell wall biogenesis [9].

Ultimately, the plant cell morphology is determined by the composition and structure of the cell wall that governs the cell expansion direction and rate. As in land plants, the primary cell wall of $M$. denticulata Bréb. consists mainly of pectins [10,11], cellulose microfibrils [12], hemicelluloses [13] and arabinogalactan proteins (AGPs) $[10,13]$. The secondary cell wall owes it rigidness to cellulose microfibrils originating from rosettes organized as hexagonal arrays $[14,15]$, whereas mixed-linked glucan is the dominant hemicellulose [13]. 
In land plants, expansins are important regulators of turgor-driven cell wall expansion. These cell wall proteins comprise a large multigene superfamily consisting of four families (EXPA, EXPB, EXLA and EXLB) of which the evolutionary relationships are well characterized [16,17]. They are unique in their ability to loosen the cell wall non-enzymatically by disrupting hydrogen bonds that link the cellulose and hemicellulose wall components [18-21]. Land plant expansins consist of two domains and a secretion signal. The $\mathrm{N}$-terminal expansin domain 1 and the $\mathrm{C}$-terminal expansin domain 2 are homologous to the catalytic domain of glycoside hydrolase family 45 (GH45) proteins and a domain present in a family of grass pollen allergens, identified as a putative cellulose binding site [22], respectively. Expansins play a role in tissue development [23,24] and in growth of suspension-cultured cells [25,26]. Although genes encoding expansin-like proteins have been recently identified in green algae transcriptomes [27], their physiological function and phylogenetic relationships with land plant expansins remain unknown.

Here, we explore the molecular basis of cell morphogenesis and cell wall formation in synchronized M. denticulata cells by means of a cDNA-amplified fragment length polymorphism (cDNA-AFLP)-based quantitative transcriptome analysis [28]. Several cell wall-related genes, among which expansins, were identified. Examination of the expansins provided the first structural, phylogenetic and functional data on green algal homologues within this gene family.

\section{Results \\ CDNA-AFLP expression profiling}

First we developed a synchronization protocol to monitor the cell morphogenesis-related gene expression in $M$. denticulata. The protocol was based on the observation that the majority of the cells grown in a 14-h light/ 10-h dark regime divided during the second dark period, after the growth medium of a stationary culture (obtained after 3-4 weeks) had been refreshed and, concomitantly, the cell density reduced at the start of the light period. Replacing the dark period by a light period enhanced the amount of synchronically dividing cells (Figure 1B). The effect of cell density on synchronization was significant (GLM; $F$-test; $P<0.001$ ), with an optimal cell density below 80 cells $\mathrm{mL}^{-1}$. Following synchronization, up to $85 \%$ of the cell population divided during an 8- to 9-h period, showing a sigmoid course (Figure $1 \mathrm{C}$, D; Additional file 1). By sampling this period at five consecutive time points we obtained samples with different proportions of cells at the major morphogenetic stages (Figure 1A,C,D). cDNA-AFLP expression profiling of these samples allowed the assignment of differentially expressed genes to either the onset of cell division (Figure 1A2; Figure $2(\mathrm{C} 1 \mathrm{a}$ and $\mathrm{C} 1 \mathrm{~b})$ ), the bulge (Figure 1A3; Figure 2 (C2)), the lobe (Figure. 1A4-A9; Figure 2 (C3)), or the doublet stage, during which the secondary cell wall is formed (Figure 2 ( $\mathrm{C} 4$ and $\mathrm{C} 5)$ ). In total, the relative abundance was monitored of 4574 transcriptderived fragments (TDFs) during the cell growth of $M$. denticulata (Figure 3, Additional file 2), for which the expression patterns were altered visibly across time in 1420 and significantly $(P<0.009 ; Q<0.05)$ in 476 TDFs. According to other studies [29,30], we estimate that two-thirds of the mRNA population was sampled, implying that the real number of genes differentially expressed during cell growth of $M$. denticulata could be $\sim 2100$. A high similarity (E-value $<1$.E-01 and similarity $>50 \%)$ to database entries with assigned identities and unknown or hypothetical genes was found for 107 and 22 TDFs, respectively, mostly with Embryophytes and not with Chlorophyta. However, the majority of the TDFs (324 or $71.5 \%$ ) showed no sequence similarity to any database entry (Figure 3; Additional file 3). Plausible explanations might be sequences too short to reveal any significant identity, short sequences representing nonconserved portions of genes, TDFs originating from the 3'-untranslated region of a gene, or TDFs representing genes specific to $M$. denticulata or streptophytic algae. Of the 129 annotated genes, 118 clustered into six groups (designated C1a, C1b, C2, C3, C4, and C5) (Figure 2) according to the timing of their highest expression (Figure $1 C, D)$. Except for one cluster consisting of six genes (cluster $\mathrm{C} 1 \mathrm{~b}$; Figure 2), the expression profiles were reproducible in the two independent sampling series. The few genes not included in one of the described clusters typically showed narrow temporal expression patterns.

Based on their annotation, the TDFs were classified into 14 functional categories, named according to the Gene Ontology terminology (http://www.geneontology. org) (Figure 3; Additional file 3). The association between the functional category and the TDF clustering was not significant $\left(\chi^{2}\right.$ test; $\left.p=0.070\right)$. The major group with a significant hit was involved in cell wall metabolism. The second largest category corresponded to sequences sharing significant similarity to unknown or hypothetical proteins.

Of 18 TDFs with similarity to genes involved in cell wall biogenesis or cell pattern formation, the RNA samples of the second CDNA-AFLP replication series and on an independently sampled series (Additional file 1) were analyzed by real-time quantitative reverse-transcription (qRT)-PCR. In general, the expression profiles obtained by cDNA-AFLP and qRT-PCR (Additional file 4) corresponded well (Additional file 5), confirming the obtained expression results. 


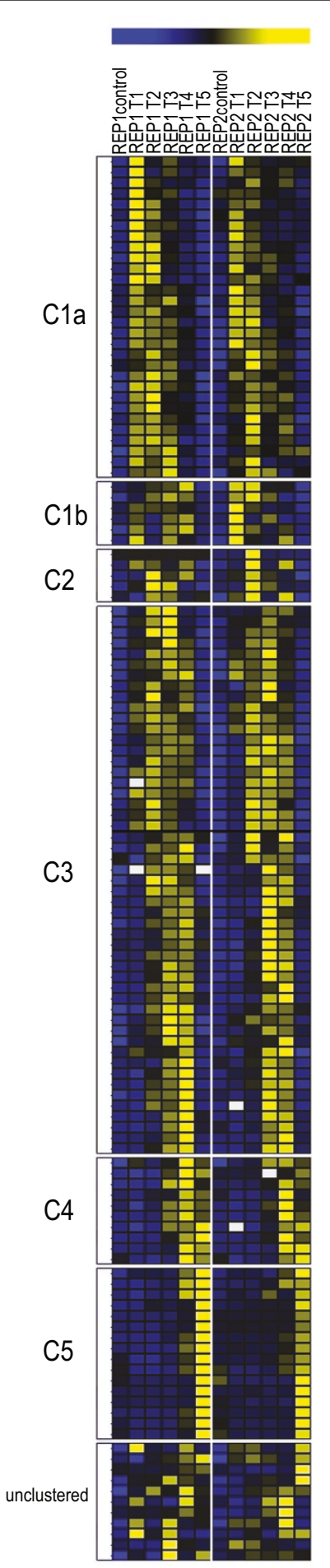

Figure 2 Adaptive quality-based clustering of annotated cell growth-modulated TDFs. Each row represents the relative transcript accumulation measured for each TDF across the two replicated time series. Yellow and blue, transcriptional activation and repression relative to the average expression level over the time course, respectively; white, missing data. Cluster names (C1 to C5) are indicated on the left.
A

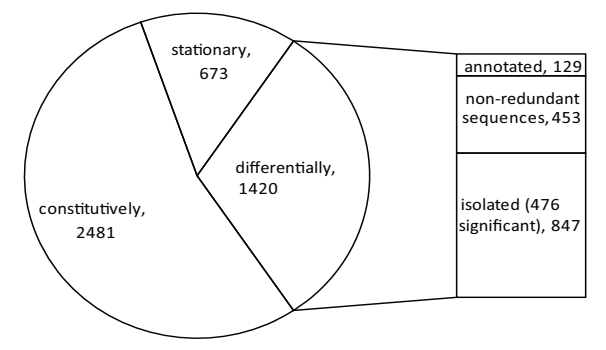

B

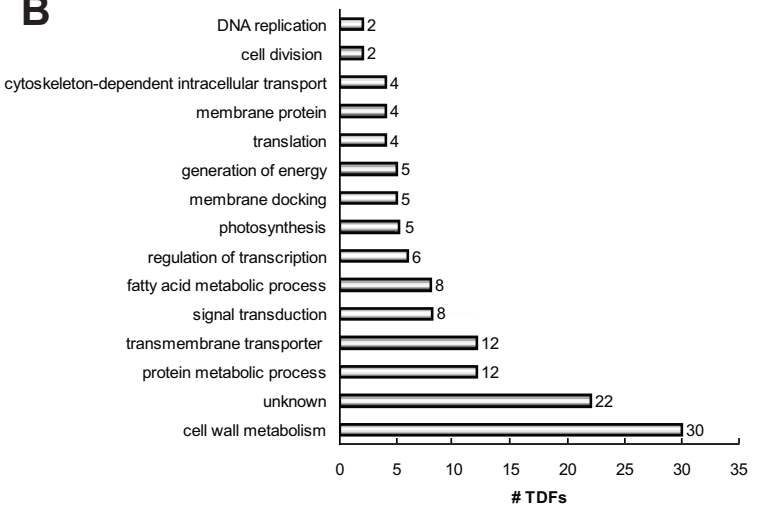

Figure 3 Transcript derived fragments (TDFs) identified by CDNA-AFLP analysis of Micrasterias denticulata cell growth. (A)

In total, 4574 TDFs were scored, of which 2481 were constitutively expressed, 673 only in stationary cultures and 1420 displayed altered expression patterns across time (476 significantly; $P<0.009$; $Q<0.05)$. Of the latter group, 847 were isolated from gel. From 453 non-redundant sequences, 129 could be annotated. (B) Functional classification of the 129 annotated transcript-derived fragments (TDFs) differentially modulated during cell growth.

\section{Genes relevant for cell pattern formation}

Seven TDFs could be identified that might be relevant for cell pattern formation in $M$. denticulata, among which two members of the Rab GTPase cycle and two members of the SNARE cycle of membrane fusion reactions. Rab8, similar to $M d 1852$, is known to be involved in post-Golgi transport to the plasma membrane, inducing the formation of new surface extensions and believed to be regulated by a guanine nucleotide dissociation inhibitor [31] possibly corresponding to $M d 0818$. Both $M d 1852$ and Md0818 belonged to cluster $\mathrm{C} 1 \mathrm{a}$ and, thus, had increased mRNA levels before the onset of mitosis. This observation might be related to the determination of the basic symmetry of a $M$. denticulata cell before mitosis, indicated by the development of a three-lobed semicell after removal of the nucleus [32]. In contrast, the SNARE cycle members were highly expressed in cluster C3, pointing to a role in further differentiation during the 
lobe stages for $M d 1404$ (similar to plant syntaxin 32) and Md1560 (similar to a regulatory AAA-type of ATPase).

Two TDFs were identified encoding putative glycophosphatidylinositol (GPI) anchors: $M d 4071$ and $M d 4341$, belonging to clusters $\mathrm{C} 1 \mathrm{a}$, and $\mathrm{C} 4$, respectively. Among other properties, the function of a GPI anchor might be its dominant targeting to a specific membrane domain [33], possibly establishing a membrane template for morphogenesis. Md4341 turned out to be a 179amino-acid protein containing a signal peptide and a fasciclin domain (a putative cell adhesion domain) (Evalue 2.9E-07), with similarity to a fasciclin-like and an AGP-like protein from Brachypodium sylvaticum [CAJ26371.1] and Arabidopsis thaliana [AAM62616.1], respectively (Additional file 6).

Md3533 (cluster C3), similar to a very-long-chain fatty acid-condensing enzyme, might be involved in morphogenesis in accordance to the essential role in cell expansion during plant morphogenesis of Arabidopsis [34].

\section{Genes involved in cell wall metabolism}

A total of 30 cell wall-related genes were identified. Six TDFs operating in the monosaccharide metabolism, evenly distributed over $\mathrm{C} 1$ and $\mathrm{C} 3$, could be identified as UDP-pyrophosphorylases ( $M d 1739, M d 2333$, and $M d 2565)$, a phosphoglucomutase ( $M d 2842)$, a rhamnose synthase (Md1089), and a GDP-mannose 3,5-epimerase (Md3053). Nine polysaccharide synthesis enzymes all nearly clustered in C3, among which two cellulose synthases, $M d 0757$ (see also [35]) and $M d 3668$, and one cellulose synthase-like (CSL) gene of the CSLC family, $M d 2838$. The exostosin family glycosyltransferases $M d 0450, M d 1114, M d 2144$, and the glycosyltransferase Md0257 might synthesize the hemicellulosic or pectinous part of the cell wall and mucilage as well that is pectic in nature [11] and secreted simultaneously with cell wall material during cell growth [36]. Md3598 was the $\alpha$-1,6-xylosyltransferase, typical of the hemicellulose biosynthetic pathway, whereas $M d 0888$ was the xyloglucan endotransglycosylase/hydrolase (XET/XTH) that is a xyloglucan-modifying enzyme. The open reading frame (ORF) of Md0888 encoded a 277-amino-acid protein with a signal peptide and a GH16-XET domain (E-value 6.10E-37) and therefore designated MdXTH1. The catalytic site DEIDFEFLG, conserved among GH16 family members [37] and most seed plant XTHs [38] was present in MdXTH1 as xExDxEFxG and immediately followed by a potential N-glycosylation site NxT/S [39] (Additional file 7). The other 15 identified TDFs were involved in wall assembly, reorganization, and selective degradation. Four of them gave significant hits with expansins: MdEXP1 (C4), MdEXP2 (C4), MdEXP3 (C3), and MdEXP4 (C3). Whereas MdEXP4 and MdEXP3 were expressed during the early morphogenetic stages
(C3), MdEXP1 and MdEXP2 were up-regulated during later stages (C4) (Figure 4). Changes in the internal structure of the cell walls, required for cell expansion, might be achieved by the release of hydroxyl radicals mediated by the class-III peroxidases $M d 0434$ and Md0493. Peroxidase-generated hydroxyl radicals could cause non-enzymatic wall loosening by cleavage of various polysaccharides [40]. The ORF of Md0434 contained a secretion signal peptide and a Pfam peroxidase domain (E-value 2.50E-97) (Additional file 8). The $\mathrm{H}_{2} \mathrm{O}_{2}$ substrate for the peroxidase activity was probably generated by the glyoxal oxidases $M d 0606, M d 1709$, and $M d 3495$. Hydrolytic enzymes included the pectinesterase $M d 4415$, the endo- $\beta$-1,6-galactanase $M d 1480$, and two members of cluster C5: the polygalacturonidase $M d 3500$ and the $\beta$-glucosidase $M d 0559$, possibly involved in degradation of a connecting zone between the primary and the secondary cell wall, thereby enabling shedding of the primary cell wall [41].

\section{Phylogenetic relationship of $M$. denticulata expansin- resembling proteins}

As the involvement of expansins in cell growth of green algae had not been examined previously, we concentrated the experiments on this class of proteins. The full length characteristics of the $M$. denticulata expansin-resembling proteins ( $M d \mathrm{EXPs}$ ) are given in Additional file 9. MdEXP1 and MdEXP4 exhibited the highest sequence similarity (74\% identity, 84\% similarity) (Figure 5).

Phylogenetic analysis of the first dataset revealed that all $M d$ EXPs were recovered as a monophyletic group with high support $(\mathrm{BV}=99, \mathrm{PP}=1.00)$ (Figure $6 \mathrm{~A})$. The

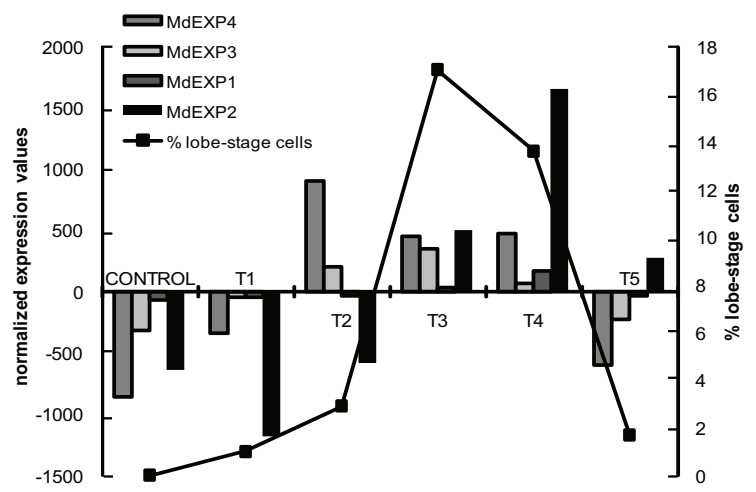

Figure 4 Normalized cDNA-AFLP expression values of Micrasterias denticulata expansin-resembling proteins in synchronized cultures in relation to the proportion of lobeforming cells in these cultures. The samples (T1-T5) are defined in Figure 1D. 
Micrasterias and Spirogyra sequences fell within the plant expansins and were most closely related to the EXPA family, with which they formed a well supported clade $(\mathrm{BV}=86, \mathrm{PP}=1.00)$. The $M d \mathrm{EXPs}$ are recovered sister to the EXPA clade and the Spirogyra sequences form a paraphyletic assemblage, but the relationships between the Micrasterias and Spirogyra expansins and the EXPA clade are poorly supported. The high sequence divergence of expansins within and among Micrasterias and Spirogyra is shown by the relatively longer branches than those within the EXPA clade. In the second dataset, the putative expansin sequences of Chlorophyta formed a highly divergent clade, separated from the plant expansins by a very long branch (Additional file 10). Although the relationships between the Chlorophyta clade, the Dictyostelium clade and the plant expansin families were poorly resolved, the phylogenetic position of the Micrasterias clade, closely allied to the EXPA family, was well supported.

\section{Domain organization of the $M$. denticulata expansin-} resembling proteins

The structural domain organization of the different $M d$ EXPs was compared with the characteristic structural features of plant expansins (Table 1, Figure 5, Figure 7). A secretion signal peptide was present in all of them (Figure 5, Figure 7, Table 1). While the pollen-allerg-1 domain occurred in all proteins, except MdEXP4, the GH45 domain was found in MdEXP2 and MdEXP3 only, albeit with insignificant E-values. Nevertheless, in all sequences, a DPBB-1 domain was present, a rare lipoprotein A-like double-psi beta-barrel, to which GH45 belongs, and even twice in MdEXP2 (Additional file 11). The eight cystenyl residues forming disulfide bridges in fungal GH45 enzymes and maintaining their folded structure [16] were conserved in the expansin domain 1 of some of the plant expansin groups [22] and also in the MdEXPs (Figure 5). In $M$. denticulata, the GGACGY motif was present as GGSCGY/F, whereas 


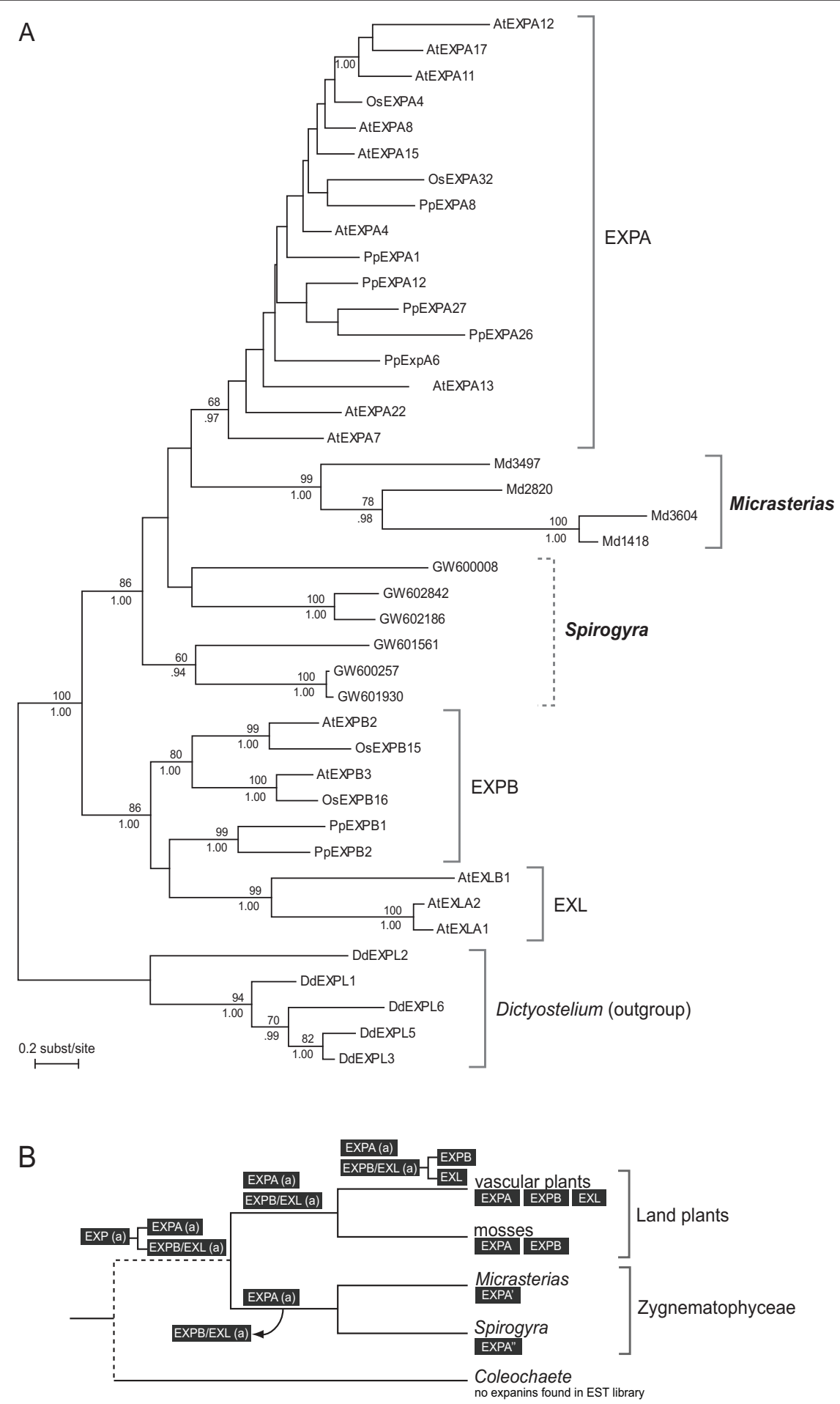

Figure 6 Maximum likelihood phylogeny of the plant expansin gene family (A) Maximum likelihood (ML) phylogeny of the plant expansin gene family, showing the phylogenetic position of the Micrasterias and Spirogyra genes. Numbers at nodes indicate ML bootstrap values (top) and Bayesian posterior probabilities (bottom); values below 50 and 0.9, respectively, are not shown. Dd, Dictyostelium discoideum (outgroup); Pp, Physcomitrella patens; Os, Oryza sativa; At, Arabidopsis thaliana. (B) Possible events hypothetically explaining the distribution of expansin gene families in land plants and Zygnematophyceae. The organismal tree is based on multigene phylogenetic analyses [5,6] and only includes taxa in which expansins have been found, along with Coleochaete that apparently lacks expansins based on transcriptome analyses [27]. The dotted line in the tree indicates phylogenetic uncertainty. "(a)" marks ancestral gene families, EXPA' and EXPA" represent the EXPA-related genes found in Micrasterias and Spirogyra respectively. 
Table 1 Characteristics (domains and motifs) of the Micrasterias denticulata expansin-resembling proteins

\begin{tabular}{|c|c|c|c|c|}
\hline Characteristic & MdEXP1 & MdEXP2 & MdEXP3 & MdEXP4 \\
\hline Signal peptide & $1-24$ & $1-23$ & $1-19$ & $1-24$ \\
\hline GH45 domain & No & $39-180$ & $52-211$ & No \\
\hline Eight conserved cysteines & Yes & Yes & Yes & Yes \\
\hline GGACGY motif & GGsCGY & GGsCGf & GGsCGY & GGsCGY \\
\hline GxxCGxCF/Y motif & Yes & Yes & Yes & Yes \\
\hline Y/FRRVPC motif & IYAVSC & FTQVPC & VTRVPC & VYAAGC \\
\hline Catalytic site key residues & No & $1 \mathrm{~A}$ & $1 \mathrm{~A}$ & No \\
\hline DPBB_1 domain & $51-132$ & $56-136 ; 302-385$ & $82-161$ & $51-132$ \\
\hline Pollen_allerg_1 domain & $144-223$ & $147-226$ & $172-253$ & No \\
\hline Four conserved tryptophan $(\mathrm{W})$ residues (* structurally related residues) & $2(\mathrm{~W}) 1\left(\mathrm{~F}^{*}\right) 1\left(\mathrm{Y}^{*}\right)$ & $2(\mathrm{~W}) 1\left(\mathrm{~F}^{*}\right) 1\left(\mathrm{Y}^{*}\right)$ & $2(\mathrm{~W}) 2\left(\mathrm{Y}^{*}\right)$ & No \\
\hline HATFYG motif (A) & No & No & No & No \\
\hline$\alpha$-insertion (A) & Yes & Yes & Yes & Yes \\
\hline$\beta$-insertion (B) & No & No & No & No \\
\hline HFDL motif (A, B) & Only L & Only L & Only L & Only L \\
\hline CDRC motif (LA) & No & No & No & No \\
\hline Long carboxy terminal extension (LA) & No & Yes & No & No \\
\hline
\end{tabular}

When a domain is present, its position is given (starting from the first methionine). A, unique characteristic of the EXPA family; $B$, unique characteristic of the EXPB family; LA, unique characteristic of the EXLA family; LB, unique characteristic of the EXLB family

the GxxCGxCF/Y motif in the same expansin domain 1 was fully conserved. A third motif characteristic for this domain, the Y/FRRVPC motif, varied among the $M d$ EXPs (Table 1). The key residues of the GH45 catalytic site, conserved among EXPA and EXPB proteins (see Figure 5, indicated in bold), were absent. In land plant expansins, the pollen-allergen domain contains four conserved tryptophan residues that form part of the hydrophobic core of this domain [42] (Figure 5). In the $M d$ EXPs up to two of these residues occurred and were fully conserved, when the structurally related amino acids phenylalanine and tyrosine are taken into

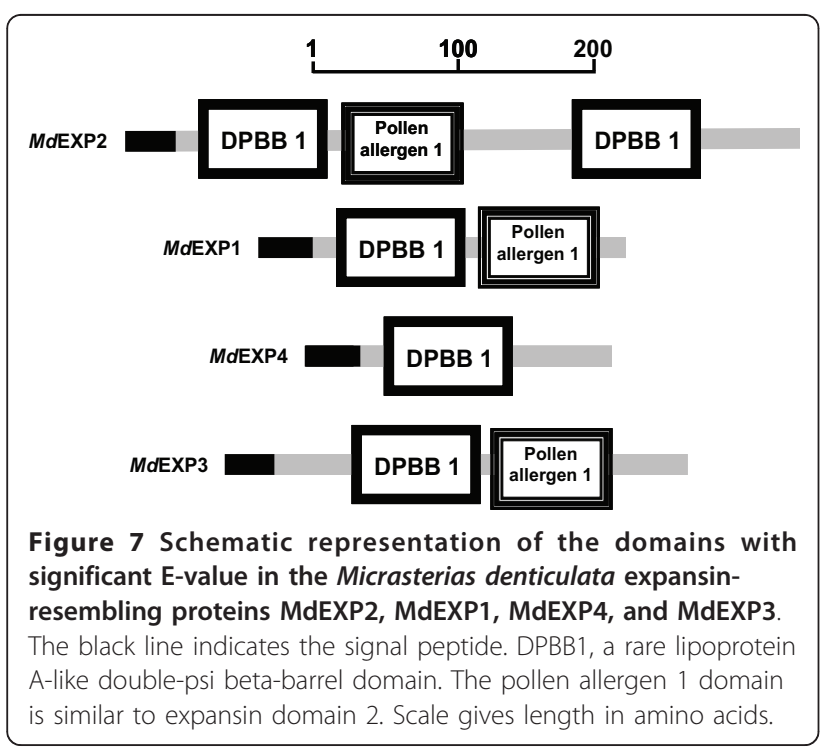

account (Figure 5, Table 1). Although the highly conserved HATFYG motif near the $\mathrm{N}$-terminus is characteristic of EXPA proteins [22], this motif could not be found in the MdEXPs. The EXPA and EXPB proteins were distinguished by the presence or absence of short stretches of amino acids at conserved positions at either side of the HFDL motif in the GH45 active site ( $\alpha$ - and $\beta$-insertions) $[16,43]$. According to the phylogeny, the $M d$ EXPs contained an $\alpha$-insertion characteristic of EXPAs, but they lacked the four highly conserved Nterminal residues 'GWCN' found in other EXPAs [16]. Of the HFDL motif, only the leucine residue was conserved (Figure 5). However, the long C-terminal extension of MdEXP2 was typical for EXLA proteins [22]. Although $M d$ EXPs were heterogeneous and divergent, they clearly shared several characteristics of the EXPA protein domains, supporting our phylogenetic results.

\section{Subcellular localization of the expansin-resembling MdEXP2 and phenotypic changes due to its overexpression}

The ORF of the $M$. denticulata expansin-resembling protein with the highest mRNA levels during cell growth, namely MdEXP2, was cloned into an overexpression vector to allow $\mathrm{C}$-terminal fusions to the green fluorescence protein (GFP) [35]. As observed by confocal laser scanning microscopy of transiently $M d E X P 2-$ GFP-overexpressing interphase cells, the MdEXP2-GFP fluorescence occurred as motile cytoplasmic dots (Figure 8; Additional file 12) but could not be observed in the secondary cell wall itself, probably because of quenching due to a low apoplast $\mathrm{pH}$ [44]. Therefore, MdEXP2- 

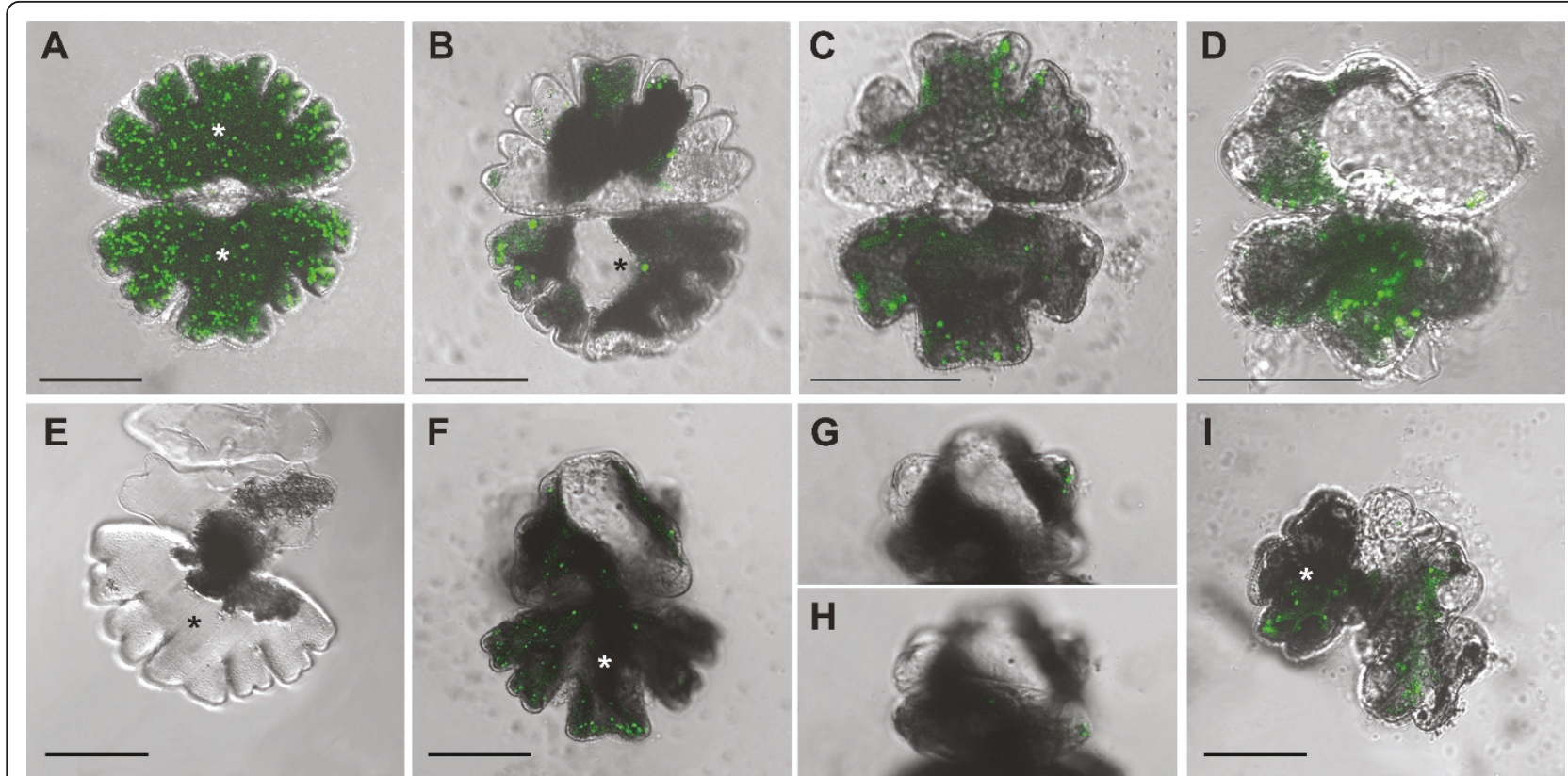

Figure 8 Phenotypes of Micrasterias denticulata cells transiently overexpressing MdEXP2-GFP observed by confocal fluorescence microscopy. Merged transmission light and GFP fluorescence single optical sections (B-I) or projection (A). Initial semicells not formed under MdEXP2-GFP overexpression marked by asterisk. (A) Undivided MdEXP2-GFP overexpressing cell. (B-I) Phenotypes of M. denticulata cells transiently overexpressing MdEXP2-GFP arranged according to phenotype severity. (B) Cell line 11. Upper semicell formed after the first cell division, exhibiting stimulated lobe elongation. The lobes are stretched and rounded instead of flattened at their tips. (C-E) Elongation growth is reduced, lateral lobes are fused. (C) Cell line 6. Lower semicell formed after the second, upper semicell after the third cell division. (D) Cell line 7. Lower semicell formed after the first, upper semicell after the second cell division. (E) Cell line 18. Upper semicell resulting from the first cell division, after which the cell died. (F-I) Cell line 13. Loss of growth polarity and planarity upon cell division. (G, H) Other focal sections of (F) showing that there are three growth planes instead of one. (I) Semicells fused upon the second cell division. Scale bar $=50 \mu \mathrm{m}$.

GFP-overexpressing interphase cells were processed for transmission electron microscopy (TEM) and stained with GFP antibodies and protein A-gold to investigate whether the MdEXP2-GFP protein localizes into the secondary cell wall. Indeed, a positive signal was observed in the secondary cell wall, albeit not abundantly (Figure 9A,B), probably due to the instability of the GFP protein in this acid compartment [44]. In addition, mucilage vesicles still attached to distal Golgi cisternae (Figure 10A) and some released from the dictyosome (Figure 10C,D) were stained. This immunogold labelling indicated that the punctate pattern of the GFP fluorescence (Figure 8A) could correspond to Golgi-derived mucilage vesicles and that the fusion protein was directed to the wall via the endoplasmic reticulum-Golgi secretory pathway. No staining was observed in experiments for specificity control consisting of sections treated with protein A-gold alone (Figure 10B). In control sections of transgenic cells producing the free GFP, labelling occurred in the cytoplasm and was absent from the cell wall and cell organelles (Figure 9C,D).

Next, 26 independent transient transgenic cells were isolated and further analysed (Additional file 13). A group of cells lost the GFP-fluorescence within a few days and divided, resulting in normal daughter cells, while the majority of the cells died, possibly because of strong MdEXP2 overexpression as indicated by their bright GFP fluorescence. However, in eight independent cell lines, a range of phenotypes related to $M d E X P 2$ overexpression during cell division and growth could be observed. Line 11 exhibited strong lobe elongation without loss of growth polarity after the first cell division (Figure $8 \mathrm{~B}$ ). The lobes were stretched and rounded instead of flattened at their tips. After the second cell division of line 11 and in all other cases (lines 6, 7, 8, $12,13,18,19)$, the growth polarity was altered. Line 13 lost its planarity upon cell division and, thus, had the most severe phenotype. New semicells, without the characteristically lobed morphology, but almost without indentations, grew out three-dimensionally. Upon a new cell division of one of the daughter cells, the same phenotype was observed, whereas the newly formed semicells were also fused with each other (Figure 8F-I). In lines $6,7,8,11$ (from the second cell division onwards), 12,18 , and 19 axial but not radial elongation was impaired, resulting in semicells with a stunted polar lobe and fused lateral lobes (Figure 8C-E). Sometimes, the second division gave rise to a similar morphology 


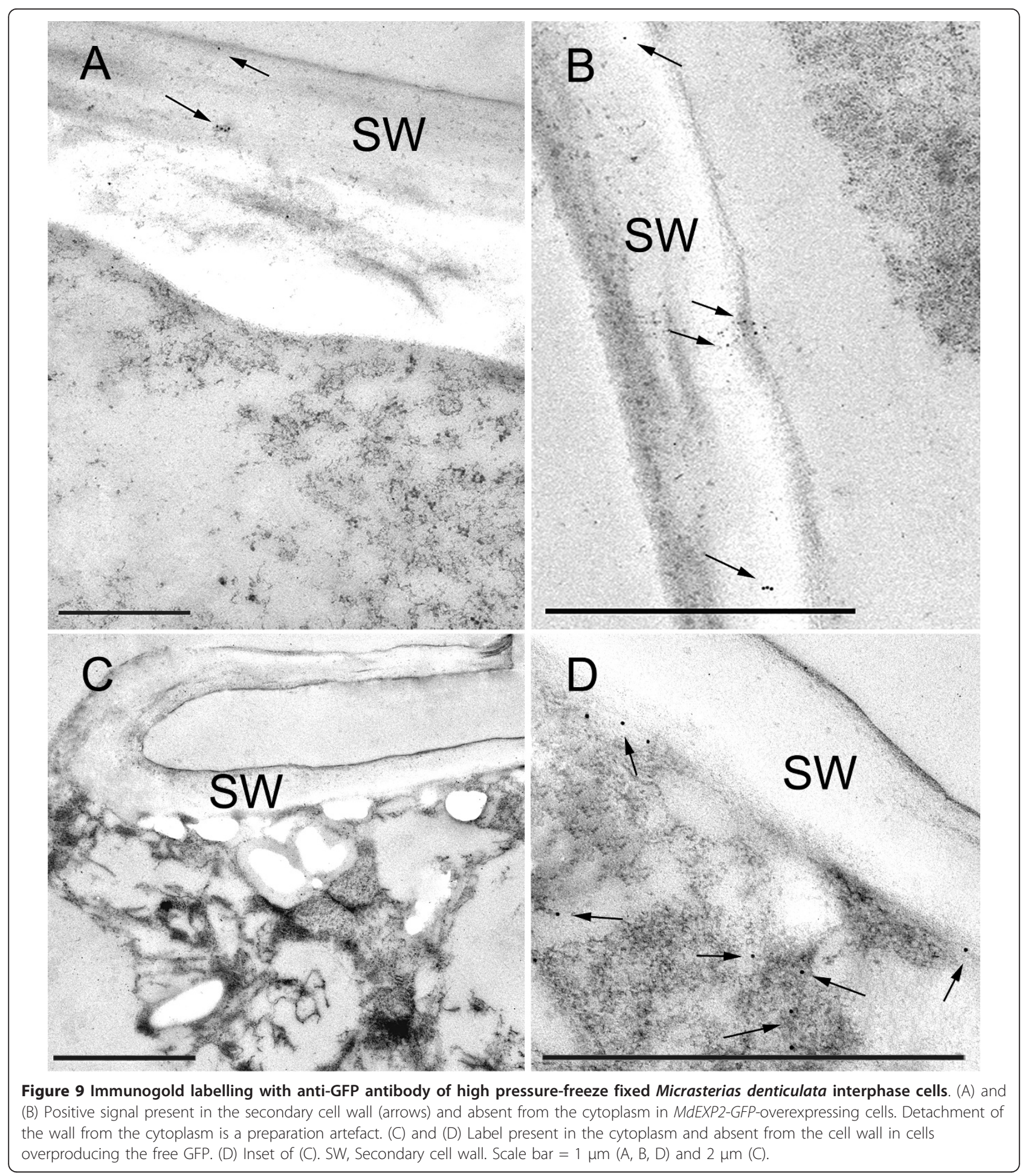

(Figure 8D), but in most cases the phenotype was lost over one to two subsequent generations (Figure 8C). That all phenotypes still had the GFP signal and none of them resulted from control experiments with transgenic cells expressing only the GFP [35] suggests that they were related to the expression of the transgene.

\section{Discussion}

Genome-wide expression analysis revealed a role for Rab and SNARE cycles in membrane fusions and for AGP-like proteins in cell pattern establishment. AGPs, differing in composition from land plants, had recently been found to be present in the growing primary cell wall of Micrasterias 


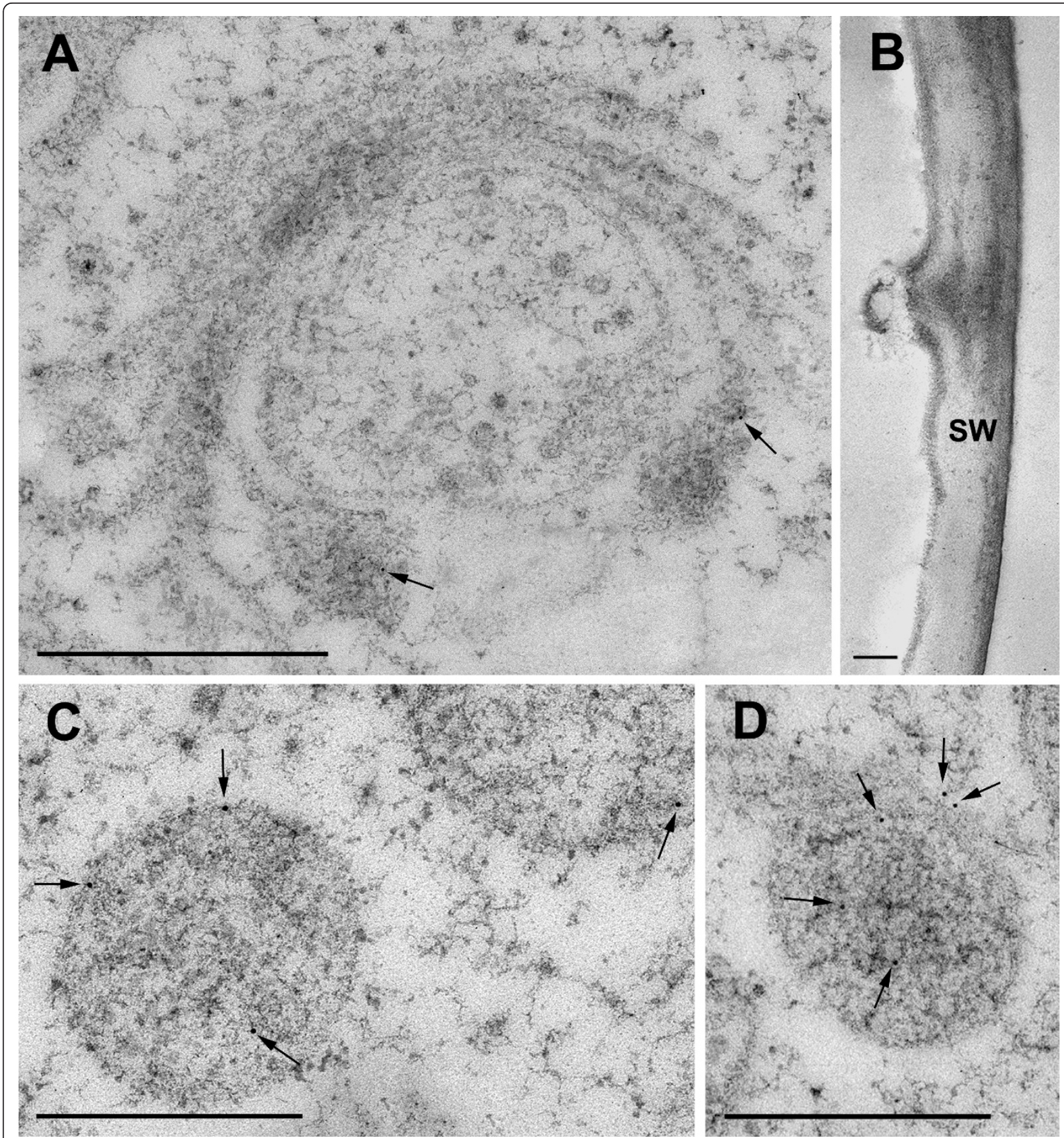

Figure $10 \mathrm{Immunogold}$ labelling with anti-GFP antibody of high pressure-freeze fixed transiently MdEXP2-GFP-overexpressing Micrasterias denticulata interphase cells. (A) No staining of dictyosomal cisternae, fine staining of vesicles attached to the dictyosome (arrows). (B) Control staining with protein A-gold alone. No signal. SW, Secondary cell wall. (C, D) Staining of a mucilage vesicle released into the cytoplasm. Arrows indicate the label. Scale bar $=1 \mu \mathrm{m}$.

[13]. Our analysis further suggests an involvement of classIII peroxidases, XTH and expansins in cell wall growth. Class-III peroxidases had been considered absent in green algae [45], although a (partial) mRNA occurred in the desmid Closterium [46]. Here, a full length algal class-III peroxidase is linked to cell growth. Furthermore, despite their supposed lack of xyloglucans [47], XET activity was found in the streptophyte Chara and the chlorophyte Ulva [48]. Recently, the $(1 \rightarrow 3,1 \rightarrow 4)-\beta$-glucan (mixed linked glucan, MLG) has been determined as the main constituent of the secondary cell wall of Micrasterias [13] and in this study, the first algal XTH was identified. 
The green algae Valonia (Chlorophyta) and Nitella (Streptophyta) exhibit acid-induced wall extension, but this response is seemingly not mediated by proteins $[49,50]$. Contrary to the assumption of a land plant specific mechanism [20], four genes with significant similarity to expansins were up-regulated during cell growth of Micrasterias, in agreement with a presumed ancient evolutionary origin [16]. Based on significant BLAST similarities with the expansin domains [22], global pairwise alignment and phylogeny, and structural features like the presence of a secretion signal, MdEXP2, MdEXP1, and MdEXP3 are considered expansins, but considerably diverge in gene architecture from embryophytic expansins, as indicated by both domain analysis and phylogeny. These results add to the evidence that expansins are not strongly conserved through evolution [17]. The key residues of the GH45 domain catalytic site and the HFDL motif, which are present in land plants and Spirogyra, do not occur in Micrasterias. The HFDL motif is present in most groups of plant expansins, but is absent in a few plant EXPA and EXPB proteins [16]. The eight $\mathrm{N}$-terminal cysteines required for protein folding [16] and the four C-terminal tryptophans or related residues involved in cellulose binding [42] are conserved between Micrasterias, Spirogyra and land plants and can be considered as key characteristics of plant expansins. The GGxCGY/F and the GxxCGxCF/Y motifs in the GH45 domain are conserved as well. The only constant difference in the conserved amino acid residues in Micrasterias when compared to land plants is the occurrence of a serine residue instead of an alanine residue in the GGACGY motif of the GH45 domain. As expansins disrupt noncovalent bonding between cellulose microfibrils and matrix glucans that stick to the microfibril [18], we hypothesize that the characteristics of the $M d$ EXPs might be related to the dominant MLG in the secondary cell walls of Micrasterias [13] instead of the $(1 \rightarrow 4)-\beta$-glucan backbone present in dicotyledonous plants. The occurrence of MLG in lichens [51], fungi [52], green algae (Micrasterias) [13], horsetails [53], and Poales [54] has been suggested to result from convergent evolution [55], whereas the occurrence of distinct $M d \mathrm{EXPs}$ might be connected to two different (primary and secondary) cell wall types, implied by their different temporal expression patterns.

Based on the present expansin phylogeny, combined with current hypotheses on the evolution of the closest relatives to land plants [6,56], expansins can fairly be assumed to have evolved before the origin of land plants. However, the unresolved relationships between Embryophytes and the streptophyte lineages Zygnematophyceae, Coleochaetophyceae and Charophyceae [57] hamper a solid reconstruction of expansin gene history. Assuming that the Zygnematophyceae form the closest living relatives to land plants [8], a possible scenario would be that expansins evolved into two lineages (EXPA and EXPB + EXL) in a common ancestor of Embryophytes and Zygnematophyceae (Figure 6B). The apparent lack of EXPB and EXL in Micrasterias and Spirogyra might be due to gene loss, early in the evolution of the Zygnematophyceae. It should be emphasized however, that the ancient relationships among expansin families are difficult to resolve. Therefore the phylogenetic positions of the green algal expansin-resembling genes should be interpreted with care, hinting at a complete divergence of the plant expansin families within the embryophytic lineage.

Distinct differences in gene architecture between Micrasterias and embryophytic expansins have raised the question whether the biochemical functions of $M d$ EXPs and embryophytic expansins are similar. To this end, we studied functionally $M d E X P 2$, the $M d E X P$ with the highest expression levels during growth, through localization and overexpression. A GFP antibody detecting the MdEXP2-GFP fusion protein was used, because the sequence conservation was too low for the available plant expansin antibodies. Unfortunately, currently, because only transient genetic transformation of Micrasterias is possible [35], immunoelectron microscopic detection in the growing cell walls is unfeasible. Nevertheless, the ectopically produced protein was targeted to the fully-grown secondary cell wall. In addition, the phenotypic results obtained from its overexpression suggest that MdEXP2 can alter the cell wall shape, but this effect on growth cannot be excluded to result from saturation or blockage of the membrane trafficking of other essential proteins. The phenotypes were remarkably variable, whereby the phenotype severity did not seem to directly correlate with expansin abundance (as inferred from MdEXP2-GFP fluorescence intensity), as reported previously [58-62]. Although a phenotype could be observed corresponding to the expected enhanced wall extensibility due to increased expansin levels [19], the elongation growth impaired in most cases, but not the lateral expansion, resulting in the fusion of the lateral lobes. A number of factors might explain the reduced growth of tomato (Solanum lycopersicum) overexpressing an expansin [59]. All together, the growth phase-specific expression, the accumulation in the cell walls, and its overexpression phenotype, allow us to to hypothesize that MdEXP2 might have a biochemical function related to that of land plant expansins.

\section{Conclusions}

Our study provides novel data on gene expression during morphogenesis and cell growth in the desmid Micrasterias denticulata and adds to our understanding 
of the evolution of genes involved in cell wall formation in green algae and land plants.

Cell walls have played crucial roles in the colonization of land by plants $[63,64]$. For a detailed understanding of how cell walls have evolved, cell wall components and cell wall-related genes in land plants and their closest relatives, the streptophyte green algae need to be analyzed comprehensively. Although some cell wall components appear to be adaptations of land plants, cell wall evolution after the colonization of land is seemingly characterized by the elaboration of a pre-existing set of genes and polysaccharides rather than by substantial innovations [65-68]. The data add to the growing body of evidence that the evolutionary origins of many cell wall components and regulating genes in embryophytes antedate the colonization of land.

\section{Methods}

\section{Culture conditions, synchronization and sampling}

A clonal Micrasterias denticulata culture was grown in twofold diluted Desmidiaceae medium [69] at $23^{\circ} \mathrm{C}$ and 120-140 $\mu \mathrm{mol}$ photons. $\mathrm{m}^{-2} . \mathrm{s}^{-1}$ under a 14-h light/10-h dark regime.

Two independent cultures were synchronized by replacing the growth medium of a stationary culture, diluting the density, and extending the light period to $24 \mathrm{~h}$. Cells were sampled from synchronized cultures for RNA extraction at five consecutive time points during growth (T1 to T5) that were chosen to include for each time point a different proportion of cells at different morphogenetic stages (bulge, lobe, and doublet stage) (Figure 1C, D). Two independent stationary cultures served as control samples. Cells were concentrated by centrifugation for $1 \mathrm{~min}$ at $4^{\circ} \mathrm{C}$ and $4000 \mathrm{rpm}$ and washed with phosphate buffered saline (PBS). Cell pellets were snap-frozen in liquid nitrogen and stored at $-70^{\circ} \mathrm{C}$.

\section{RNA extraction and CDNA-AFLP analysis}

Total RNA was isolated from approximately 80,000 frozen cells at each time point as described [70] with slight modifications. Instead of $\beta$-mercaptoethanol, $2 \mathrm{M}$ stock solution of the anti-RNase agent dithiothreitol was added to the extraction buffer to a final concentration of $50 \mathrm{mM}$ [71]. Cells were disrupted and homogenized in a bead mill (Retsch) (5 min at frequency $30 \mathrm{~s}^{-1}$ ) with silicone-carbide sharp particles (Biospec Products) after the cell pellet had been thawed and suspended in the extraction buffer. Phytopure resin (GE-Healthcare) was added during the first chloroform:isoamylalcohol extraction to eliminate mucilage contamination of the RNA [72]. RNA samples were controlled qualitatively with the RNA 6000 Nano kit of the Bioanalyzer 2100 (Agilent Technologies) and quantified with the ND-1000 UV-Vis Spectrophotometer (Nanodrop).
Starting from $2 \mu \mathrm{g}$ of total RNA, cDNA synthesis and cDNA-AFLP analysis with $B s t \mathrm{YI}$ and $M s e \mathrm{I}$ as restriction enzymes were done according to the procedures as described [28]. For the selective amplification, BstYI + $\mathrm{C} / \mathrm{T}+1 /$ Mse $\mathrm{I}+2$ primer pairs were used, resulting in 128 primer combinations. The cDNA-AFLP fingerprints were visualized with an autoradiography platform (PhosphorImager 445 SI; Molecular Dynamics).

Scanned gel images were quantitatively analyzed with the AFLP-QuantarPro image analysis software (Keygene N.V.). Expression values per gene were normalized for replicate effects by subtracting the replicate mean value (Additional file 2). Average linkage hierarchical clustering with the TMeV v4 software (http://www.tm4.org) and adaptive quality-based clustering (minimum two tags in a cluster, 0.95 significance level) [73] of the normalized expression data were carried out.

To assess the effect of the various cell division stages (T1-T5) on the gene expression during synchronized growth, a linear regression model of the form $y=\mu+$ rep + time $+\varepsilon$ was fitted to the data, where $y$ represents the raw expression values, rep and time the fixed replicate and time effects, respectively, and $\varepsilon$ the random error. For all TDFs, a $F$-statistic was calculated, $P$-values were assigned to the main term time and subsequently transformed into false discovery rates, and Q-values [74] (Additional file 2). Besides the TDFs with a significant $(Q<0.05)$ differential expression across the five time points, TDFs that were clearly absent in the stationary cultures but present during the synchronized growth, were excised from the dried gels, irrespective the significance of their differential expression across the five stages, followed by amplification and subsequent sequencing [28].

The TDFs were designated by $M d$ (for $M$. denticulata) followed by a number corresponding to the AFLP fragment. After mutual alignment of the sequences, only the longest one of a group of identical sequences was retained, except when the TDFs displayed different expression profiles. Each sequence was identified by a similarity search against the public databases with the Blast2GO v1.7.2 program (http://www.Blast2GO.de) [75]. In addition to hits displaying an E-value < 1.E-03, hits with E-values between 1.E + 00 and 1.E-03 and a similarity $>50 \%$ were retained for further analysis.

\section{Real-time qRT-PCR assay}

Primers (Additional file 14) were designed with the Beacon Designer 7.0 (PREMIER Biosoft International) and the Oligo PerfectTM Designer (Invitrogen). Isolated RNA was treated with DNaseI (GE-Healthcare). An aliquot of $1 \mu \mathrm{g}$ of total RNA from each sample was used for cDNA synthesis. The reverse transcription was carried out with oligo-dT primers and the SuperscriptTM 
II reverse transcriptase (Invitrogen) according to the manufacturer's instructions.

A set of reference genes was selected, based on their constitutive expression pattern during morphogenesis, to serve as a normalization factor in quantitative reverse-transcription-(qRT)-PCR analysis. Their expression stability $(M)$ was analyzed with the geNormTM program [76]. Among 10 constitutively expressed TDFs, Md0789 (similar to a reticulon of Arabidopsis thaliana) and $M d 1473$ (similar to peroxiredoxin 6 of Norway rat [Rattus norvegicus]) ( $M$ value $=0.421$ and 0.489 , respectively) were the two most stably expressed genes, followed by $M d 0386$ (similar to the unknown gene of $A$. thaliana at5g13390 t22n19_40). To determine the number of internal control genes necessary for reliable data normalization, the pairwise variation value between two sequential normalization factors $V_{2 / 3}$ was calculated with geNormTM and turned out to be 0.151 under our experimental conditions, slightly higher than the cut-off value of 0.15 . The inclusion of a fourth internal control gene resulted in an increase of the pairwise variation, yielding a $V_{3 / 4}$ value of 0.129 . As a result, the use of the two or three most stably expressed genes was considered to be sufficient for reliable data normalization [76]. PCR fragments were amplified in triplicate on the LightcyclerTM 480 (Roche Applied Science) platform with SYBRTM Green QPCR Master Mix (Stratagene), according to the manufacturer's instructions with cycling conditions of $10 \mathrm{~min}$ preincubation at $95^{\circ} \mathrm{C}$ and 45 cycles at $95^{\circ} \mathrm{C}$ for $10 \mathrm{~s}, 58^{\circ} \mathrm{C}$ for $15 \mathrm{~s}$, and $72^{\circ} \mathrm{C}$ for $15 \mathrm{~s}$. Amplicon dissociation curves were recorded by heating from $65^{\circ} \mathrm{C}$ to $95^{\circ} \mathrm{C}$. qBaseTM [77] was used for relative quantification.

\section{RACE PCRs, protein domain identification, sequence alignment and phylogenetic analyses}

The ends of the cDNAs were obtained by rapid amplification of cDNA ends (RACE) PCRs with plasmid DNA from a cDNA library of growth-synchronized $M$. denticulata (purchased from Invitrogen) as template. For $M d E X P 1, M d E X P 3$, and Md0434 only 5' RACE PCR was done, because the TDF contained the stopcodon and a part of the 3' untranslated region. For $M d 4341$, $M d X T H 1, M d E X P 2$, and MdEXP4 both 5' RACE and 3' RACE were necessary. Gene-specific primers were designed with the eprimer3 program [78] and used in combination with vector-specific (pDONR222.1) primers (Additional file 15) in a PCR consisting of 1 min preincubation at $95^{\circ} \mathrm{C}$ and 30 cycles at $95^{\circ} \mathrm{C}$ for $30 \mathrm{~s}, 54^{\circ} \mathrm{C}$ for $30 \mathrm{~s}$ and $72^{\circ} \mathrm{C}$ for $2 \mathrm{~min} 30 \mathrm{~s}$, followed by 1 cycle at $72^{\circ} \mathrm{C}$ for $5 \mathrm{~min}$.

Protein domains in the ORF sequences were identified with the SMART tool (http://smart.embl-heidelberg.de/) $[79,80]$. Signal sequences were confirmed with the
SignalP 3.0 Server (http://www.cbs.dtu.dk/services/SignalP) $[81,82]$ and iPSORT prediction (http://ipsort.hgc. jp/) [83].

Similar sequences were retrieved from GenBank (http://www.ncbi.nlm.nih.gov) using protein BLAST and tblastx [84] (Additional file 16). The sequences were aligned using MUSCLE [85]. To remove signal peptides and $\mathrm{C}$-terminal extensions, the alignment was trimmed from a conserved tryptophan near the $\mathrm{N}$-terminus to a conserved phenylalanine near the C-terminus [17].

Two sets of alignments were considered for the phylogenetic analyses. The first dataset consisted of the four $M$. denticulata expansin-resembling proteins ( $M d \mathrm{EXPs}$ ), 26 land plant expansins representing the 17 orthologous clades within the four land plant expansin families [22], and six EST sequences of the streptophyte green alga Spirogyra pratensis that showed significant similarity to land plant expansins [27]. Five expansin-like sequences of the social amoeba, Dictyostelium discoideum, were selected as outgroup based on their inferred relationship with land plant expansins $[16,86]$. This alignment was 227 amino acids long (Additional file 17). The second dataset included all sequences of the first alignment plus nine putative expansin genes found in four species of Chlorophyta (the sister clade of the Streptophyta) (322 amino acids long; Additional file 18) and was used to assess the phylogenetic position of other putative expansin sequences of green algae.

Models of protein evolution were selected with ProtTest 1.4 [87]. Maximum likelihood (ML) and Bayesian phylogenetic inference (BI) were analyzed under a WAG model of amino acid substitution with among site rate heterogeneity (gamma distribution with eight categories) for all datasets with PhyML v2.4.4 [88] and non-parametric bootstrapping (1000 replicates) to assess statistical support of internal branches with MrBayes 3.1.2 [89], respectively. Two parallel runs, each consisting of four incrementally heated chains were run for $2 \times 10^{6}$ generations, sampling every 1000 generations. Convergence of log-likelihoods was assessed in Tracer v1.4 [90]. A burn-in sample of 500 trees (well beyond the point at which convergence of parameter estimates had taken place) was removed before the majority rule consensus trees were constructed.

\section{Overexpression of MdEXP2 and microscopy}

The ORF of MdEXP2 was cloned into the SpeI restriction site (ACTAGT) of the vector pSA405A under the control of the chlorophyll $a / b$-binding protein encoding gene of the desmid Closterium and was C-terminally fused to the green fluorescence protein gene (GFP) [35]. Primers were: forward primer 5'-ATGACTAGTATGAAAATCGGCATAATCCA-3' and reverse primer 5'GGAACTAGTTAGGCACCCATTAACGGC-3'. The 
PCR was 2 min preincubation at $94^{\circ} \mathrm{C}$ and 5 cycles at $94^{\circ} \mathrm{C}$ for $45 \mathrm{~s}, 45^{\circ} \mathrm{C}$ for $45 \mathrm{~s}$, and $68^{\circ} \mathrm{C}$ for $3 \mathrm{~min}$, followed by 30 cycles at $94^{\circ} \mathrm{C}$ for $45 \mathrm{~s}, 55^{\circ} \mathrm{C}$ for $45 \mathrm{~s}$, and $68^{\circ} \mathrm{C}$ for $2 \mathrm{~min}$, and by 1 cycle at $72^{\circ} \mathrm{C}$ for $5 \mathrm{~min}$. The recombined plasmid was introduced into $M$. denticulata by microparticle bombardment [35].

For confocal microscopy, a 100M microscope (Zeiss) was used, equipped with the LSM510 software version 3.2. Samples were scanned with a $20 x$ (numerical aperture of 0.5 ) and a $63 \mathrm{x}$ water corrected objective (numerical aperture of 1.2). GFP fluorescence was visualized with argon laser illumination at $488 \mathrm{~nm}$ and a 500 to $530 \mathrm{~nm}$ band emission filter.

For transmission electron microscopy (TEM), a GFP antibody (Rb, (ab6556) Abcam) compatible protocol was followed to prepare the samples. MdEXP2-GFP-overexpressing $M$. denticulata cells were embedded in a yeast paste in a membrane carrier (Leica) and frozen immediately in a high-pressure freezer (EM PACT; Leica Microsystems). Freeze substitution was carried out in a Leica EM AFS instrument. Samples were infiltrated at $4^{\circ}$ C stepwise in LR-White, hard grade (London Resin Company Ltd.) and embedded in capsules. Ultrathin sections of gold interference color were cut with an EM UC6 ultramicrotome (Leica) and collected on formvarcoated copper mesh grids. Grids were floated on blocking solution followed by incubation in a 1:25 and 1:10 dilution (in $1 \%$ bovine serum albumin in PBS) of primary antibodies (GFP antibody, (Rb, (ab6556) Abcam) for $60 \mathrm{~min}$. The grids were labelled with protein A-10nm gold (PAG10nm) (Cell Biology Department, Utrecht University). Control experiments consisted of treating sections with PAG10nm alone. Sections were poststained in an automatic contrasting instrument (EM AC20; Leica Microsystems $\mathrm{GmbH}$ ) for $30 \mathrm{~min}$ in uranyl acetate at $20^{\circ} \mathrm{C}$ and for $7 \mathrm{~min}$ in lead stain at $20^{\circ} \mathrm{C}$. Grids were viewed with a 1010 transmission electron microscope (JEOL) operating at $80 \mathrm{kV}$.

Newly obtained sequence data were deposited in GenBank; the transcript derived fragments under accession numbers HE578289 to HE578716, the reference genes under accession numbers HE580226 to HE580228, and the open reading frames under accession numbers HE578717 to HE578726.

\section{Additional material}

Additional file 1: Distribution of morphogenetic stages in the RNA samples used for CDNA-AFLP, replication 2, and real-time qRT-PCR Additional file 2: Expression values of all scored TDFs. Additional file 3: Similarities of cDNA-AFLP fragments to database sequences.

Additional file 4: Raw real-time qRT-PCR expression values.
Additional file 5: Comparison of the expression profiles of selected TDFs obtained by CDNA-AFLP and QRT-PCR for the samples of replication 2 .

Additional file 6: Full-length deduced amino acid sequence of Md4341 aligned with its relevant BLAST hits.

Additional file 7: Full-length deduced amino acid sequence of MdXTH1 (Md0888) aligned with its relevant BLAST hits.

Additional file 8: Full-length deduced amino acid sequence of Md0434 aligned with its relevant BLAST hits.

Additional file 9: Characteristics of the expansin-resembling genes from Micrasterias denticulata.

Additional file 10: Unrooted maximum likelihood phylogeny showing the relationship of putative chlorophytan expansin sequences (with significant similarity to plant expansins in tblastx searches) with the plant expansin gene family.

Additional file 11: Protein BLAST alignment of MdEXP2 with its best hit, showing the expansin-like C-terminal extension.

Additional file 12: Confocal GFP fluorescence time lapse images (30 $s$ apart) illustrating the motility of the MdEXP2-GFP containing intracellular compartments.

Additional file 13: Features of transgenic cell lines overexpressing the MdEXP2-GFP fusion gene.

Additional file 14: Primer sequences of selected Micrasterias denticulata TDFs used for real-time qRT-PCR assay.

Additional file 15: Primers used for RACE PCR and cloning

Additional file 16: Accession numbers of the sequences used to construct the phylogenetic trees and additional Physcomitrella patens sequences.

Additional file 17: Nexus file with the MUSCLE alignment used in this study for phylogenetic analyses of expansins.

Additional file 18: Nexus file of the MUSCLE alignment used in this study for phylogenetic analyses of expansins including sequences of the Chlorophyta.

\section{Acknowledgements}

The authors thank Debbie Rombaut and Sofie D'hondt for assistance with the CDNA-AFLP analysis, Andy Vierstraete and Wilson Ardilez-Diaz for sequencing, Filip Waumans for constructing a database for the sequences identified in this study, Klaas Vandepoele for help with bioinformatics, Mansour Karimi for cloning advice, Ellen Cocquyt for phylogenetic advice, Daniel Cosgrove for nomenclatural advice, and Martine De Cock for help in preparing the manuscript. This work was supported by the Interuniversity Attraction Poles Programme (UIAP VI/33), initiated by the Belgian State, Science Policy Office, the Research Foundation-Flanders (postdoctoral fellowship grants to F.L. and L.D.V.), and the Agency for Innovation by Science and Technology in Flanders ("Strategisch Basisonderzoek" project SBO040093 and predoctoral fellowships to K.V., M.J.J.H., and J.G.).

\section{Author details}

'Laboratory of Protistology and Aquatic Ecology, Department of Biology, Ghent University, 9000 Gent, Belgium. 'Department of Plant Systems Biology, VIB, 9052 Gent, Belgium. ${ }^{3}$ Department of Plant Biotechnology and Bioinformatics, Ghent University, 9052 Gent, Belgium. ${ }^{4}$ Phycology Research Group, Department of Biology, Ghent University, 9000 Gent, Belgium. ${ }^{5}$ Plant Physiology Division, Cell Biology Department, University of Salzburg, 5020 Salzburg, Austria.

\section{Authors' contributions}

KV carried out the molecular genetic studies and drafted the manuscript. $\mathrm{MJJH}$ participated in the real-time qRT-PCR assay and genetic transformation. RDR carried out the immunoelectron microscopy. MV designed the CDNA AFLP study and performed the statistical analyses. FL carried out the phylogenetic analysis. JP and AG participated in the RACE PCRs. UL-M 
participated in the synchronization and RNA-extraction and in the interpretation of the data. JG and LDV participated in the design of the experiments. DI and WV conceived and supervised the study. WW, FL, LDV and $\mathrm{MH}$ helped to draft the manuscript. All authors read and approved the final manuscript.

Received: 5 May 2011 Accepted: 25 September 2011 Published: 25 September 2011

\section{References}

1. Dupuy L, Mackenzie J, Haseloff J: Coordination of plant cell division and expansion in a simple morphogenetic system. Proc Natl Acad Sci USA 2010, 107:2711-2716.

2. Yang Z, Fu Y: ROP/RAC GTPase signaling. Curr Opin Plant Biol 2007 10:490-494.

3. Kryvych S, Nikiforova V, Herzog M, Perezza D, Fisahn J: Gene expression profiling of the different stages of Arabidopsis thaliana trichome development on the single cell level. Plant Physiol Biochem 2008, 46:160-173.

4. Karol KG, McCourt RM, Cimino MT, Delwiche CF: The closest living relatives of land plants. Science 2001, 294:2351-2353.

5. Turmel M, Pombert JF, Charlebois $P$, Otis C, Lemieux C: The green algal ancestry of land plants as revealed by the chloroplast genome. Int J Plant Sci 2007, 168:679-689.

6. Rodríguez-Ezpeleta N, Philippe $H$, Brinkmann H, Becker B, Melkonian M: Phylogenetic analyses of nuclear, mitochondrial, and plastid multigene data sets support the placement of Mesostigma in the Streptophyta. Mol Biol Evol 2007, 24:723-731.

7. Finet C, Timme RE, Delwiche CF, Marlétaz F: Multigene phylogeny of the green lineage reveals the origin and diversification of land plants. Curr Biol 2010, 20:2217-2222.

8. Wodniok S, Brinkmann H, Glockner G, Heidel A, et al: Origin of land plants: Do conjugating green algae hold the key? BMC Evol Biol 2011, 11:104.

9. Meindl U: Micrasterias cells as a model system for research on morphogenesis. Microbiol Rev 1993, 57:415-433.

10. Lütz-Meindl U, Brosch-Salomon S: Cell wall secretion in the green alga Micrasterias. J Microsc 2000, 198:208-217.

11. Eder M, Lütz-Meindl U: Pectin-like carbohydrates in the green alga Micrasterias characterized by cytochemi cal analysis and energy filtering TEM. J Microsc 2008, 231:201-214

12. Giddings $T H \mathrm{Jr}$, Brower $\mathrm{DL}$, Staehelin LA: Visualization of particle complexes in the plasma membrane of Micrasterias denticulata associated with the formation of cellulose fibrils in primary and secondary cell walls. J Cell Biol 1980, 84:327-339.

13. Eder $M$, Tenhaken $R$, Driouich $A$, Lütz-Meindl U: Occurrence and characterization of arabinogalactan-like proteins and hemicelluloses in Micrasterias (Streptophyta). J Phycol 2008, 44:1221-1234.

14. Kim NH, Herth W, Vuong $\mathrm{R}$, Chanzy $\mathrm{H}$ : The cellulose system in the cell wall of Micrasterias. J Struct Biol 1996, 117:195-203.

15. Nakashima J, Heathman A, Brown RM Jr: Antibodies against a Gossypium hirsutum recombinant cellulose synthase (Ces A) specifically label cellulose synthase in Micrasterias denticulata. Cellulose 2006, 13:181-190.

16. Li Y, Darley CP, Ongaro V, Fleming A, Schipper O, Baldauf SL, McQueenMason SJ: Plant expansins are a complex multigene family with an ancient evolutionary origin. Plant Physiol 2002, 128:854-864.

17. Carey RE, Cosgrove DJ: Portrait of the expansin superfamily in Physcomitrella patens: comparisons with angiosperm expansins. Ann Bot 2007, 99:1131-1141.

18. McQueen-Mason S, Durachko DM, Cosgrove DJ: Two endogenous proteins that induce cell wall extension in plants. Plant Cell 1992, 4:1425-1433.

19. McQueen-Mason SJ, Cosgrove DJ: Expansin mode of action on cell walls: Analysis of wall hydrolysis, stress relaxation, and binding. Plant Physiol 1995, 107:87-100.

20. Cosgrove DJ: Expansive growth of plant cell walls. Plant Physiol Biochem 2000, 38:109-124.

21. Cosgrove DJ: Loosening of plant cell walls by expansins. Nature 2000, 407:321-326.

22. Sampedro J, Cosgrove DJ: The expansin superfamily. Genome Biol 2005 $6: 242$

23. Pien S, Wyrzykowska J, McQueen-Mason S, Smart C, Fleming A: Local expression of expansin induces the entire process of leaf development and modifies leaf shape. Proc Natl Acad Sci USA 2001, 98:11812-11817.
24. Cho HT, Cosgrove DJ: Regulation of root hair initiation and expansin gene expression in Arabidopsis. Plant Cell 2002, 14:3237-3253.

25. Link BM, Cosgrove DJ: Acid-growth response and a-expansins in suspension cultures of Bright Yellow 2 tobacco. Plant Physiol 1998, 118:907-916.

26. Wang CX, Wang L, McQueen-Mason SJ, Pritchard J, Thomas CR: pH and expansin action on single suspension-cultured tomato (Lycopersicon esculentum) cells. J Plant Res 2008, 121:527-534.

27. Timme RE, Delwiche CF: Uncovering the evolutionary origin of plant molecular processes: comparison of Coleochaete (Coleochaetales) and Spirogyra (Zygnematales) transcriptomes. BMC Plant Biol 2010, 10:96.

28. Vuylsteke M, Peleman JD, van Eijk MJT: AFLP-based transcript profiling (cDNA-AFLP) for genome-wide expression analysis. Nat Protocols 2007 2:1399-1413.

29. Milioni D, Sado PE, Stacey NJ, Roberts K, McCann MC: Early gene expression associated with the commitment and differentiation of a plant tracheary element is revealed by CDNA-amplified fragment length polymorphism analysis. Plant Cell 2002, 14:2813-2824.

30. Breyne $P$, Dreesen $R$, Cannoot B, Rombaut D, Vandepoele K, Rombauts S, Vanderhaeghen R, Inzé D, Zabeau M: Quantitative cDNA-AFLP analysis for genome-wide expression studies. Mol Genet Genomics 2003, 269:173-179.

31. Schwartz SL, Cao C, Pylypenko O, Rak A, Wandinger-Ness A: Rab GTPases at a glance. J Cell Sci 2007, 120:3905-3910, [Err. J Cell Sci 121, 246 2008)].

32. Kallio $P$, Heikkilä $\mathrm{H}$ : On the effect of elimination of nuclear control in Micrasterias. In Plant Cells. Edited by: Bonotto S, Goutier R, Kirchmann K, Maisin JR. New York, Academic Press; 1972:167-192

33. Takos AM, Dry IB, Soole KL: Detection of glycosyl-phosphatidylinositolanchored proteins on the surface of Nicotiana tabacum protoplasts. FEBS Lett 1997, 405:1-4

34. Zheng $\mathrm{H}$, Rowland $\mathrm{O}$, Kunst $\mathrm{L}$ : Disruptions of the Arabidopsis enoyl-CoA reductase gene reveal an essential role for very-long-chain fatty acid synthesis in cell expansion during plant morphogenesis. Plant Cell 2005 17:1467-1481.

35. Vannerum K, Abe J, Sekimoto H, Inzé D, Vyverman W: Intracellular localization of an endogenous cellulose synthase of Micrasterias denticulata (Demidiales, Chlorophyta) by means of transient genetic transformation. J Phycol 2010, 46:839-845.

36. Oertel A, Aichinger N, Hochreiter R, Thalhamer J, Lütz-Meindl U: Analysis of mucilage secretion and excretion in Micrasterias (Chlorophyta) by means of immunoelectron microscopy and digital time lapse video microscopy. J Phycol 2004, 40:711-720.

37. Henrissat B, Coutinho PM, Davies GJ: A census of carbohydrate-active enzymes in the genome of Arabidopsis thaliana. Plant Mol Biol 2001, 47:55-72.

38. Nishitani $K$ : The role of endoxyloglucan transferase in the organization of plant cell walls. Int Rev Cytol 1997, 173:157-206.

39. Shakin-Eshleman SH, Spitalnik SL, Kasturi L: The amino acid at the $X$ position of an Asn-X-Ser sequon is an important determinant of $N$ linked core-glycosylation efficiency. J Biol Chem 1996, 271:6363-6366.

40. Passardi F, Longet D, Penel C, Dunand C: The class III peroxidase multigenic family in rice and its evolution in land plants. Phytochemistry 2004, 65:1879-1893.

41. Brook AJ: The Biology of Desmids. Oxford, Blackwell Scientific; 1981, Botanical Monographs, Vol. 16.

42. Toone EJ: Structure and energetics of protein-carbohydrate complexes. Curr Opin Struct Biol 1994, 4:719-728.

43. $\mathrm{Wu}$ Y, Meeley RB, Cosgrove DJ: Analysis and expression of the a-expansin and $\beta$-expansin gene families in maize. Plant Physiol 2001, 126:222-232.

44. Ward WW: Biochemical and physical properties of green fluorescent protein. In Green Fluorescent Protein: Properties, Applications and Protocols. Edited by: Chalfie M, Kain SR. New York, Wiley; 2005:39-66, Methods of Biochemical Analysis, Vol. 47.

45. Passardi F, Penel C, Dunand C: Performing the paradoxical: how plant peroxidases modify the cell wall. Trends Plant Sci 2004, 9:534-540.

46. Sekimoto H, Tanabe $Y$, Takizawa M, Ito N, Fukumoto Rh, Ito M: Expressed sequence tags from the Closterium peracerosum-strigosum-littorale complex, a unicellular charophycean alga, in the sexual reproduction process. DNA Res 2003, 10:147-153.

47. Popper ZA, Fry SC: Primary cell wall composition of bryophytes and charophytes. Ann Bot 2003, 91:1-12

48. Van Sandt VST, Stieperaere H, Guisez Y, Verbelen JP, Vissenberg K: XET activity is found near sites of growth and cell elongation in bryophytes 
and some green algae: new insights into the evolution of primary cell wall elongation. Ann Bot 2007, 99:39-51.

49. Taiz L: Plant cell expansion regulation of cell wall mechanical properties. Annu Rev Plant Physiol 1984, 35:585-657.

50. Tepfer M, Cleland RE: A comparison of acid-induced cell wall loosening in Valonia ventricosa and in oat coleoptiles. Plant Physiol 1979, 63:898-902.

51. Olafsdottir ES, Ingólfssdottir K: Polysaccharides from lichens: structura characteristics and biological activity. Planta Med 2001, 67:199-208.

52. Pettolino F, Sasaki I, Turbic A, Wilson SM, Bacic A, Hrmova M, Fincher GB: Hyphal cell walls from the plant pathogen Rhynchosporium secalis contain (1,3/1,6)- $\beta$-D-glucans, galacto- and rhamnomannans, $(1,3 ; 1,4)-\beta$ D-glucans and chitin. FEBS J 2009, 276:3698-3709.

53. Fry SC, Nesselrode BHWA, Miller JG, Mewburn BR: Mixed-linkage (1区3,1区4)$\beta$-D-glucan is a major hemicellulose of Equisetum (horsetail) cell walls. New Phytol 2008, 179:104-115.

54. Trethewey JAK, Campbell LM, Harris PJ: (1E3),(1ه4)- $\beta$-D-glucans in the cell walls of the Poales (sensu lato): an immunogold labeling study using a monoclonal antibody. Am J Bot 2005, 92:1660-1674.

55. Popper ZA, Tuohy MG: Beyond the green: understanding the evolutionary puzzle of plant and algal cell walls. Plant Physiol 2010, 153:373-383

56. Lemieux C, Otis C, Turmel M: A clade uniting the green algae Mesostigma viride and Chlorokybus atmophyticus represents the deepest branch of the Streptophyta in chloroplast genome-based phylogenies. BMC Biol 2007, 5:2.

57. Leliaert $F$, Verbruggen $H$, Zechman FW: Into the deep: new discoveries at the base of the green plant phylogeny. BioEssays 2011, 33:683-692

58. Caderas D, Muster M, Vogler H, Mandel T, Rose JKC, McQueen-Mason S, Kuhlemeier C: Limited correlation between expansin gene expression and elongation growth rate. Plant Physiol 2000, 123:1399-1413.

59. Rochange SF, Wenzel CL, McQueen-Mason SJ: Impaired growth in transgenic plants over-expressing an expansin isoform. Plant Mol Biol 2001, 46:581-589.

60. Lee $\mathrm{Y}$, Kende $\mathrm{H}$ : Expression of $\beta$-expansins is correlated with internodal elongation in deepwater rice. Plant Physiol 2001, 127:645-654.

61. Choi D, Lee Y, Cho HT, Kende H: Regulation of expansin gene expression affects growth and development in transgenic rice plants. Plant Cell 2003, 15:1386-1398.

62. Obembe OO, Jacobsen E, Visser R, Vincken JP: Expression of an expansin carbohydrate-binding module affects xylem and phloem formation. Afr J Biotechnol 2007, 6:1608-1616.

63. Kenrick P, Crane PR: The origin and early evolution of plants on land. Nature 1997, 389:33-39.

64. Graham LE, Cook ME, Busse JS: The origin of plants: body plan changes contributing to a major evolutionary radiation. Proc Natl Acad Sci USA 2000, 97:4535-4540.

65. Popper ZA, Tuohy MG: Beyond the green: Understanding the evolutionary puzzle of plant and algal cell walls. Plant Physiol 2010, 153:73-383.

66. Sørensen I, Domozych D, Willats WGT: How have plant cell walls evolved? Plant Physiol 2010, 153:366-372.

67. Popper ZA, Michel G, Hervé C, Domozych DS, Willats WGT, Tuohy MG Kloareg B, Stengel DB: Evolution and diversity of plant cell walls: From algae to flowering plants. Annu Rev Plant Biol 2011, 62:567-590.

68. Sørensen I, Pettolino FA, Bacic A, Ralph J, Lu F, O'Neill MA, Fei Z, Rose JKC, Domozych DS, Willats WGT: The Charophycean green algae provide insights into the early origins of plant cell walls. The Plant Journal 2011.

69. Schlösser UG: Sammlung von Algenkulturen. Ber Dtsch Bot Ges 1982, 95:181-276.

70. Chang S, Puryear J, Cairney J: A simple and efficient method for isolating RNA from pine trees. Plant Mol Biol Rep 1993, 11:113-116.

71. Pearson G, Lago-Leston A, Valente M, Serrão E: Simple and rapid RNA extraction from freeze-dried tissue of brown algae and seagrasses. Eur J Phycol 2006, 41:97-104.

72. Kiefer $E$, Heller W, Ernst D: A simple and efficient protocol for isolation of functional RNA from plant tissues rich in secondary metabolites. Plant Mol Biol Rep 2000, 18:33-39.

73. De Smet F, Mathys J, Marchal K, Thijs G, De Moor B, Moreau Y: Adaptive quality-based clustering of gene expression profiles. Bioinformatics 2002, 18:735-746.
74. Storey JD, Tibshirani R: Statistical significance for genome wide studies. Proc Natl Acad Sci USA 2003, 100:9440-9445.

75. Conesa A, Götz S, García-Gómez JM, Terol J, Talón M, Robles M: Blast2GO: a universal tool for annotation, visualization and analysis in functional genomics research. Bioinformatics 2005, 21:3674-3676.

76. Vandesompele J, De Preter K, Pattyn F, Poppe B, Van Roy N, De Paepe A, Speleman F: Accurate normalization of real-time quantitative RT-PCR data by geometric averaging of multiple internal control genes. Genome Biol 2002, 3, research 0034.1-0034.11.

77. Hellemans J, Mortier G, De Paepe A, Speleman F, Vandesompele J: qBase relative quantification framework and software for management and automated analysis of real-time quantitative PCR data. Genome Biol 2007, 8:R19.1-R19.14.

78. Rice P, Longden I, Bleasby A: EMBOSS: the European Molecular Biology Open Software Suite. Trends Genet 2000, 16:276-277.

79. Schultz J, Milpetz F, Bork P, Ponting CP: SMART, a simple modular architecture research tool: identification of signaling domains. Proc Natl Acad Sci USA 1998, 95:5857-5864.

80. Letunic I, Doerks T, Bork P: SMART 6: recent updates and new developments. Nucleic Acids Res 2009, 37:D229-D232

81. Nielsen H, Engelbrecht J, Brunak S, von Heijne G: Identification of prokaryotic and eukaryotic signal peptides and prediction of their cleavage sites. Protein Eng 1997, 10:1-6.

82. Bendtsen JD, Nielsen H, von Heijne G, Brunak S: Improved prediction of signal peptides: SignalP 3.0. J Mol Biol 2004, 340:783-795.

83. Bannai H, Tamada Y, Maruyama O, Nakai K, Miyano S: Extensive feature detection of $\mathrm{N}$-terminal protein sorting signals. Bioinformatics 2002, 18:298-305.

84. Altschul SF, Madden TL, Schäffer AA, Zhang J, Zhang Z, Miller W, Lipman DJ: Gapped BLAST and PSI-BLAST: a new generation of protein database search programs. Nucleic Acids Res 1997, 25:3389-3402.

85. Edgar RC: MUSCLE: multiple sequence alignment with high accuracy and high throughput. Nucleic Acids Res 2004, 32:1792-1797.

86. Ogasawara S, Shimada N, Kawata T: Role of an expansin-like molecule in Dictyostelium morphogenesis and regulation of its gene expression by the signal transducer and activator of transcription protein dd-STATa. Dev Growth Differ 2009, 51:109-122.

87. Abascal F, Zardoya R, Posada D: ProtTest: selection of best-fit models of protein evolution. Bioinformatics 2005, 21:2104-2105.

88. Guindon S, Gascuel O: A simple, fast, and accurate algorithm to estimate large phylogenies by maximum likelihood. Syst Biol 2003, 52:696-704.

89. Ronquist F, Huelsenbeck JP: MrBayes 3: Bayesian phylogenetic inference under mixed models. Bioinformatics 2003, 19:1572-1574.

90. Rambaut A, Drummond AJ: Tracer v1.4. 2007 [http://beast.bio.ed.ac.uk]].

doi:10.1186/1471-2229-11-128

Cite this article as: Vannerum et al.: Transcriptional analysis of cell growth and morphogenesis in the unicellular green alga Micrasteria (Streptophyta), with emphasis on the role of expansin. BMC Plant Biology 2011 11:128

\section{Submit your next manuscript to BioMed Central and take full advantage of:}

- Convenient online submission

- Thorough peer review

- No space constraints or color figure charges

- Immediate publication on acceptance

- Inclusion in PubMed, CAS, Scopus and Google Scholar

- Research which is freely available for redistribution

Submit your manuscript at www.biomedcentral.com/submit
C Biomed Central 